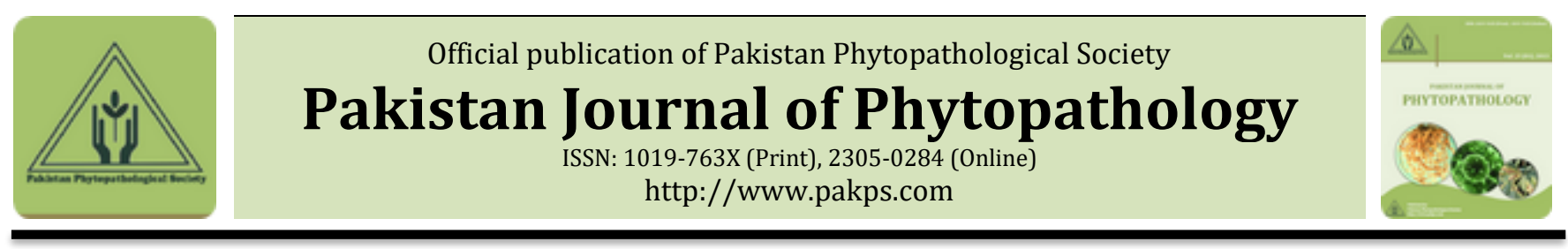

\title{
EVALUATION OF VARIOUS WHEAT LINES AGAINST LOOSE SMUT (USTILAGO TRITICI) AND ITS EPIDEMIOLOGICAL STUDIES
}

\author{
Ateeq U. Rehman, Syed A. H. Naqvi*, Ummad U. D. Umar, Rasheed Ahmed \\ Department of Plant Pathology, Bahauddin Zakariya University, Multan, Pakistan.
}

\begin{abstract}
A B S T R A C T
Fungal diseases pose a potential threat to successful cereal production in wheat particularly in Pakistan. Loose smut caused by Ustilago tritici is an important disease of wheat. During the current research various lines of wheat were screened against the deadly disease, results showed no line was resistant against the disease in the wheat genetic resources, mostly varieties showed susceptible to highly susceptible response. All the environmental variables were found conducive for the development of the disease. The disease is a serious concern for wheat production and potential breeding programs are the need of time to cater the losses due to this disease.
\end{abstract}

Keywords: Screening, epidemic, resistance, management

\section{INTRODUCTION}

Wheat (Triticum aestivum L.) is staple food crop for humans and cultivated worldwide. The wheat consumption is getting substantial part in developed nations, and developing countries, this signifies an essential supply of calories. The intake of wheat products within developing nations is growing every day. Wheat flour can also be utilized for manufacturing cookies, noodles as well as gluten. Wheat is a cereal crop widely cultivated all over the world, as compared to every other agronomic crop and also the most significant selection of food with regard to human (Bhutta and Ahmad, 1991). Wheat also includes a small variety of lipids, vitamins and minerals, the wheat-based food is considered extremely healthy, world widely (Ilyas et al., 1990). One of the numerous factors responsible for lower yield associated with wheat in the Pakistan is bad soil fertility or improper nutrient use in the soil, lake of agronomic practices or production technology and high bacterial and fungal disease attack which was reported to be of main significance (Kumar et al., 2004). Fungal

Submitted: March, 17, 2017

Revised: December, 11, 2017

Accepted for Publication: December 20, 2017

* Corresponding Author:

Email: atifhasanshah@hotmail.com

(C) 2017 Pak. J. Phytopathol. All rights reserved. diseases pose a potential threat to successful cereal production in wheat particular in Pakistan. Loose smut caused by Ustilago tritici is an important disease of wheat. This disease is very common, serious and inflicts colossal losses in production of wheat. Normally, loose smut can causes $1 \%$ damage to wheat crop but in some severe cases like humid parts of country and hilly areas, damage and loses can be $10-20 \%$ based upon cultivars under cultivation and management practices (Ziaullah et al., 2003). The disease requires cool humid weather that prolongs especially at flowering. Artificial inoculation of wheat heads with teliospores (aqueous suspension of teliospores) by various inoculation methods can develop resistance against loose smut of wheat (Mishra et al., 1990). These spores are held together by the small thin membrane. Smut fungi seldom kill their host but infected plants are mostly stunted. Most of smut fungi produce two kinds of spores and these types of spores are the basidiospores and teliospores. Smut fungi also exist in the form of races but these races are not stable due to process of meiosis in smut fungi, in meiosis, smut fungi produce new generation and these generations are further used for infection while in rust fungi, the races of rust fungi are stable and also cause severe infection in host plant (Piepenbring et al., 1998). Loose smut symptoms are not produced until at maturity or at heading stage of plant. The heads, kernals and spikelet of 
every plant is infected and due to fungal infection the whole spike is converted into black spores masses. These spores are blown off through wind and rachis remains in field (Ivanova et al., 2004). In Pakistan, two physiological races of $U$. tritici causing loose smut were first reported in 1966-67. These races were isolated from Sialkot (Hassan et al., 1970). In Pakistan, stem rust, leaf rust, loose smut and leaf blight was reported to be the most damaging diseases of wheat that causes the decline in yield up to $50 \%$ (Jamil et al., 2005). Mishra et al., (1990) reported that out of 92 cultivars that were inoculated artificially through needle method against loose smut of wheat caused by the Ustilago tritici 15 cultivars were found resistant $U$. tritici and 3 were found moderately resistant. Druzhin and Krupnov (2002) studied the effect of environment on the infection of soft spring wheat cultivars and lines by loose smut, during 1993-99 in Cis-Volga region, Russia. The infection of soft spring wheat by loose smut (U. tritici) dropped even in open-blossoming susceptible varieties, with an average air temperature during blossoming is not below 23-24 ${ }^{\circ} \mathrm{C}$, a maximum temperature of $34-39{ }^{\circ} \mathrm{C}$, and relative moisture content of air of 40-50\%. Mostly closed blossoming hindered the infection of an ovary, which in combination with resistance genes is necessary for improving the efficiency of selection of spring wheat for resistance to loose smut of wheat. Epidemiological study about loose smut is very important, it showed that the loose smut, if not controlled then the disease will Disease rating scale against loose smut (llyas et al., 1990).

\begin{tabular}{l} 
Disease intensity \\
\hline No symptoms on any plant \\
$0.1-5 \%$ plants with smutted heads
\end{tabular}

$0.1-5 \%$ plants with smutted heads 6-10\% plants with smutted heads $11-20 \%$ plants with smutted heads 21-30\% plants with smutted heads 31-50\% plants with smutted heads 51-100\% plants with smutted heads increase every year in some regions while others remain free from this disease attack (Hafiz, 1986). Keeping in view the facts, current research was conducted to evaluate various wheat germplasm against loose smut of wheat and to determine the most conducive environmental factor facilitating the disease in the field.

\section{MATERIALS AND METHODS}

Study site: The current research was conducted at Agriculture Experimental Farm, Department of Plant Pathology, Faculty of Agricultural Sciences and Technology, Bahauddin Zakaraiya University, Multan, Pakistan.

Collection of germplasm and field sowing: Fourteen lines were collected from Regional Agriculture Research Institute Bahawalpur and each variety was sown in a single plot having size of $2.1 \times 0.90 \mathrm{~m}$ and variety distance was maintained by $0.45 \mathrm{~m}$ in a randomized complete block design (RCBD) under field conditions.

Disease assessment by artificial inoculation of wheat plants: For the assessment of loose smut of wheat during the first year artificial inoculation of wheat was done in the field. The inoculum was prepared by dissolving the $1 \mathrm{~g}$ of teliospores of $U$. tritici in 1 liter of distilled water (Mishra et al., 1990). Inoculum was also prepared by dissolving the 30-35 infected heads or one gram of fungal spores in $250 \mathrm{ml}$ of distilled water. After harvesting the inoculated grains were stored for the next year sowing and the disease was calculated at three different dates.

Disease incidence was calculated by the formula: Disease Incidence $=($ DT/TT) $\times 100$ where DT is diseased tillers and TT is total tillers.

Correlation of environmental factors with loose smut: Environmental data consisting of minimum, maximum temperature, relative humidity and rainfall were recorded on weekly basis by conventional instrument installed at nearest observatory.

Area under disease progress curve: Area under disease progress curve (AUDPC) was determined by trapezoidal assimilation of percent disease severity over time for each genotype, taking into account the total crop duration evaluated (Madden et al., 2007).

$$
A U D P C=\sum_{i=1}^{n-1}\left\lceil\left(x_{i}+x_{i+1}\right) / 2\right\rceil\left(t_{i+1}-t_{i}\right)
$$

Statistical Analysis: All the collected datasets of disease incidence and environmental factors were subjected to analysis of variance to determine the relationship of 
disease incidence with the environmental variables by using SAS, 8.1 Carry Inc. USA (Steel et al., 1997).

\section{RESULTS}

In field trial, 14 wheat varieties/lines were sown and the data were collected on weekly basis in the month of March and April. In field first of all disease tiller were counted after counting the disease tillers, they are abstracted from total tillers.

Out of 14 lines evaluated for their reactions against loose smut of wheat, only four were found moderately resistant while three lines appeared to Table 1.\% Disease incidence of wheat lines against loose smut in the field

\begin{tabular}{|c|c|c|c|c|c|}
\hline \multirow{2}{*}{ Variety } & \multicolumn{3}{|c|}{ Various disease rating dates } & \multirow[b]{2}{*}{ Mean } & \multirow[b]{2}{*}{ AUDPC } \\
\hline & 17.03 .2013 & 24.03 .2012 & 31.03 .2013 & & \\
\hline 1. V-08171 & $38.72 \pm 5.92$ & $42.22 \pm 6.38$ & $47.30 \pm 6.83$ & $42.75 \pm 3.43 \mathrm{bf}$ & 596.71 \\
\hline 2. V-09087 & $32.80 \pm 4.39$ & $35.75 \pm 4.25$ & $40.10 \pm 3.79$ & $36.22 \pm 2.33 \mathrm{~g}$ & 505.47 \\
\hline 3. V-09137 & $22.54 \pm 1.10$ & $25.25 \pm 1.39$ & $28.13 \pm 1.34$ & $25.31 \pm 1.03 \mathrm{~h}$ & 354.16 \\
\hline 4. V-08214 & $40.18 \pm 4.86$ & $43.68 \pm 4.49$ & $48.36 \pm 4.34$ & $44.08 \pm 2.57$ be & 615.72 \\
\hline 5. V-010309 & $43.06 \pm 1.08$ & $46.58 \pm 1.07$ & $51.10 \pm 2.21$ & $46.92 \pm 1.40 \mathrm{~b}$ & 655.76 \\
\hline 6. V-010317 & $39.20 \pm 2.73$ & $42.28 \pm 2.33$ & $47.48 \pm 2.30$ & $42.88 \pm 1.76 \mathrm{bf}$ & 598.22 \\
\hline 7. V-010296 & $33.91 \pm 1.55$ & $37.61 \pm 1.03$ & $42.79 \pm 0.49$ & $38.11 \pm 1.40 \mathrm{fg}$ & 531.72 \\
\hline 8. V-09082 & $12.85 \pm 1.37$ & $14.55 \pm 1.44$ & $16.64 \pm 1.35$ & $14.69 \pm 0.88 \mathrm{i}$ & 205.20 \\
\hline 9. V-09091 & $38.44 \pm 3.47$ & $41.57 \pm 3.19$ & $45.99 \pm 3.24$ & $42.01 \pm 1.98 \mathrm{bf}$ & 586.60 \\
\hline 10. V-09006 & $41.02 \pm 2.23$ & $44.98 \pm 2.67$ & $51.74 \pm 3.31$ & $45.92 \pm 2.09 \mathrm{bc}$ & 639.59 \\
\hline 11.V-08212 & $12.26 \pm 0.93$ & $13.39 \pm 0.92$ & $14.74 \pm 0.63$ & $13.47 \pm 0.55 \mathrm{i}$ & 188.30 \\
\hline 12. V-09136 & $35.12 \pm 1.74$ & $39.16 \pm 1.60$ & $44.32 \pm 1.19$ & $39.54 \pm 1.53 \mathrm{efg}$ & 552.19 \\
\hline 13. V-09031 & $38.03 \pm 0.96$ & $41.29 \pm 0.77$ & $45.51 \pm 0.46$ & $41.62 \pm 1.15 \mathrm{cf}$ & 581.66 \\
\hline 14. V-WL-711 & $74.76 \pm 1.55$ & $79.65 \pm 1.63$ & $86.13 \pm 1.78$ & $80.19 \pm 1.84 \mathrm{a}$ & 1120.77 \\
\hline Mean & $35.47 \pm 1.33 c$ & $38.65 \pm 1.39 b$ & $42.98 \pm 1.51 \mathrm{a}$ & & \\
\hline
\end{tabular}

Means sharing similar letter in a row or in a column are statistically non-significant $(\mathrm{P}>0.05)$.

Table 2. Response of wheat lines against loose smut

\begin{tabular}{lcl}
\hline Level of Resistance & $\begin{array}{c}\text { Number } \\
\text { of Varieties }\end{array}$ & Name of varieties \\
\hline Highly Resistant (HR) & 0 & None \\
\hline Resistant (R) & 0 & None \\
\hline Moderately Resistant (MR) & 4 & V-09082, V-08214 \\
\hline Moderately Susceptible (MS) & 3 & V-09137, V-6346 \\
\hline Susceptible (S) & 4 & V-08171, V-09087, V-010317, V-010296, V-09091,V-09136, V-09031 \\
\hline Highly Susceptible (HS) & 3 & V-WL-711, V-010309, V-09006 \\
\hline
\end{tabular}

Correlation of environmental factors with loose smut of wheat: All the environmental factors positively correlated with the development of the disease with the passage of time in the field. The line be moderately susceptible and seven lines were found susceptible and highly susceptible. Determination of resistance source against loose smut is a common practice which reveals that source of resistance are not Spartan in wheat germplasm. The value of area under disease progress curve (AUDPC) was also calculated that was given the value 1120.77 of variety WL-711 that was highest. The lowest value of (AUDPC) in this table showed by the variety $\mathrm{V}-08212$ and that value were the 188.3 (Table 1 and 2). 


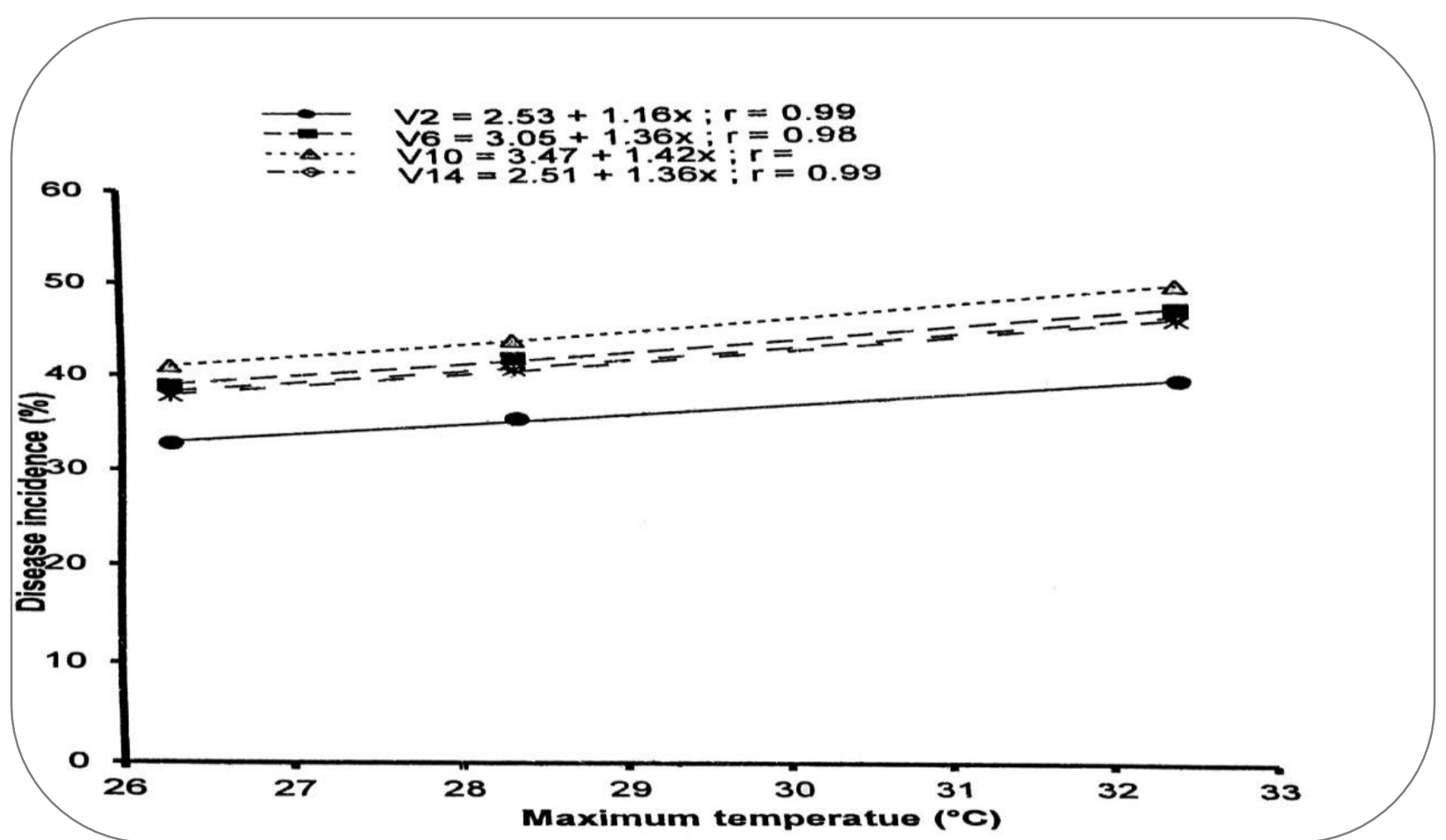

Figure 1. Relationship between maximum temperature and response values of loose smut for varieties V-2 (V-09087),

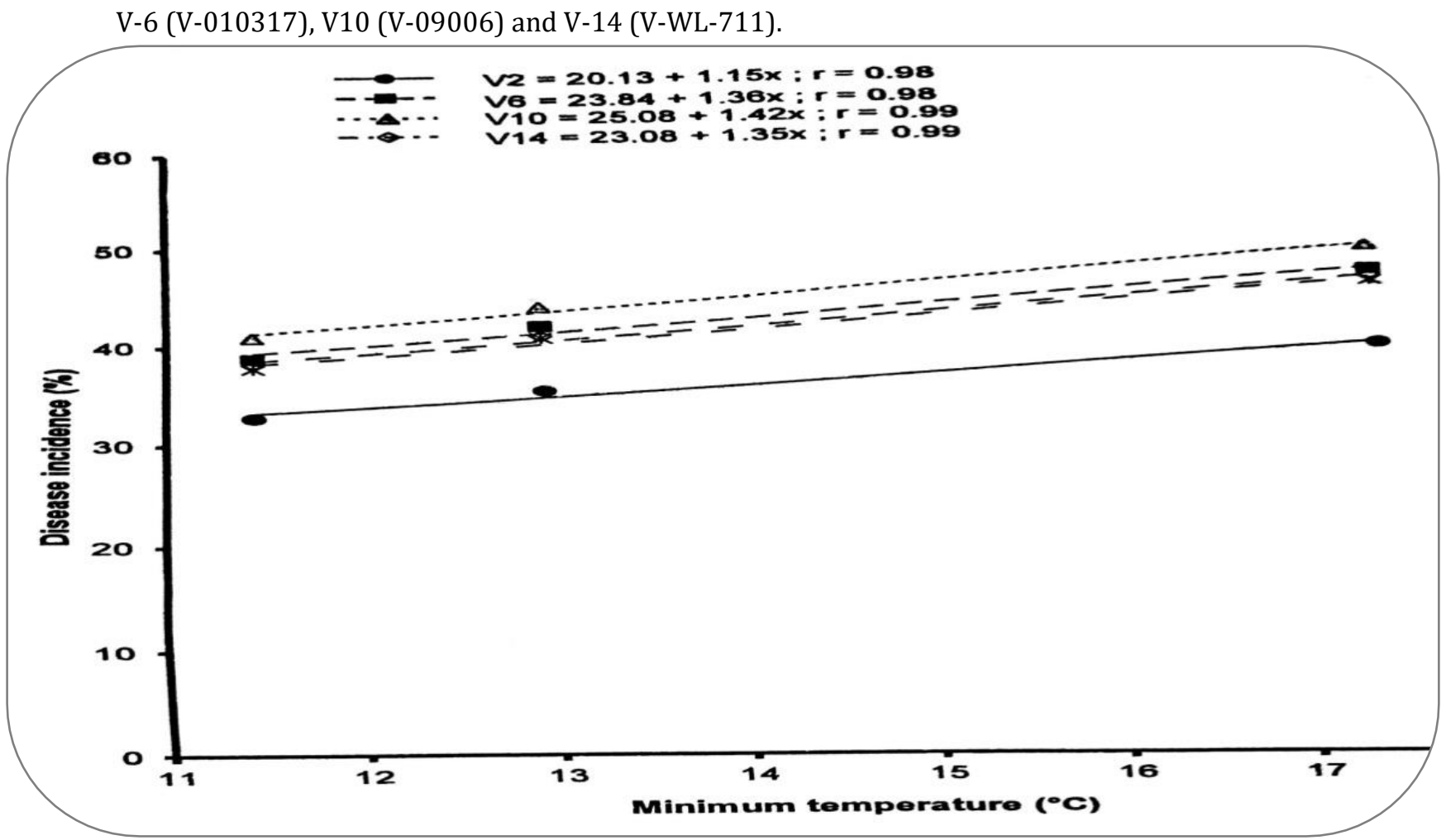

Figure 2. Relationship between minimum temperature and response values of loose smut for varieties V-2 (V-09087), V-6 (V-010317), V10 (V-09006) and V-14 (V-WL-711). 


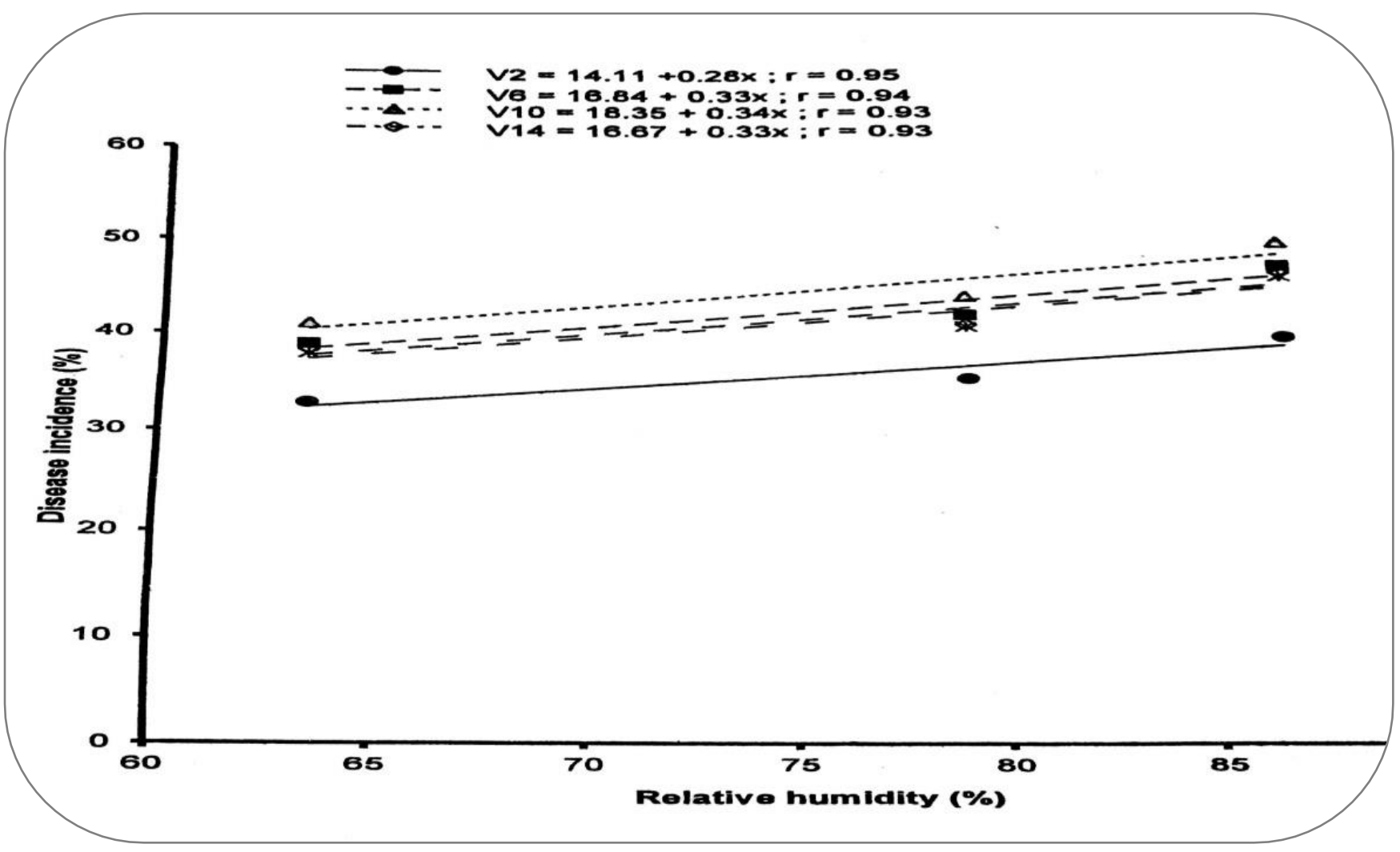

Figure 3. Relationship Between minimum relative humidity and response values of loose smut for varieties V-2 (V09087), V-6 (V-010317), V10 (V-09006) and V-14 (V-WL_711).

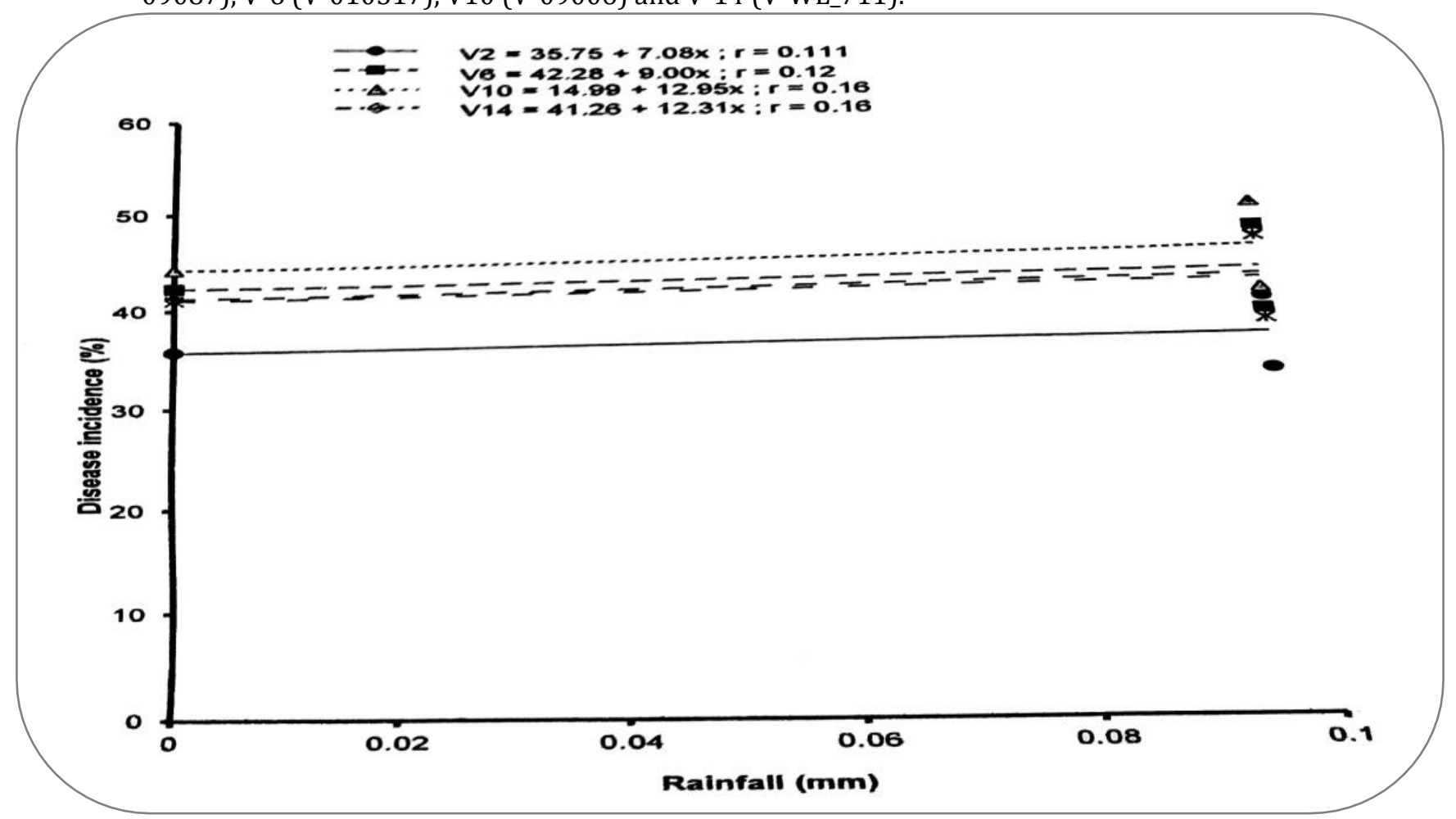

Figure 4. Relationship between rainfall $(\mathrm{mm})$ and response values of loose smut for varieties V-2 (V-09087), V-6 (V010317), V10 (V-09006) and V-14 (V-WL-711) 


\section{DISCUSSION}

Ustilago tritici is an obligate parasite hampering wheat production in all over the world. The fungi survives on wheat crop like a dormant fungal line within the embryo associated with wheat seeds. The disease causing pathogen is activated once due to contaminated seeds germinates; also it extends toward the actual growing stage from the crop plant. Apparently from blooming onwards once the plant starts form heads, the loose smut fungi invades all the younger head cells and tissues aside from that the actual rachis (backbone). Synthesis of plant growth promoting hormones and enzymes through the bacteria and especially by the loose smut fungi leads to contamination in plant heads reaching at blooming stage very quicker than healthy ones (Jamil et al., 2005). During the current research out of 14 lines evaluated for their reactions against loose smut of wheat, only four were found moderately resistant while three lines appeared to be moderately susceptible and seven lines were found susceptible and highly susceptible. Determination of resistance source against loose smut is a common practice which reveals that source of resistance are not Spartan in wheat germplasm. The value of area under disease progress curve (AUDPC) was also calculated that was given the value 1120.77 of variety WL-711 that was highest. The lowest value of (AUDPC) in this table showed by the variety V-08212 and that value were the 188.3. Similar studies were performed by Beniwal et al., (2009) who reported WH 283, WH 373 WH 343, WH 542 and PBW 343, PBW 373 and a durum variety WH 896 exhibited multiple disease resistance while Aggarwal et al., (1998) screened 539 wheat lines for the resistance to loose smut by using artificial inoculation method and found 28 wheat cultivars were resistance to loose smut after the evaluation for the period of 3 years. Ziaullah et al., (2003) directed an experiment and determined that out of 144 advance wheat genotype, 54 were highly resistant, 10 were moderately resistant, 9 moderately susceptible, 19 susceptible and 13 highly susceptible. The commercial cultivars Inqlab-91, Crs-1, Derawar-97, MH-97, Punjab-96, Faisal-85, Bwp-95 whereas Inqlab2000, Uqab-2000 and Bwp-2000 were resistant to disease. Our results are in line with Mishra et al., (1990) reported that out of 92 cultivars that were inoculated artificially through needle method against loose smut of wheat caused by the $U$. tritici, 15 cultivars were found resistant and 3 were found moderately resistant to loose smut of wheat. Bhutta and Ahmad (1991) reported that out of 78615 acres under various varieties of wheat during 1990-91 in Lahore, Khanewal, Sargodha and Rahim Yar Khan, $36.06 \%$ were free from loose smut $(U$. tritici) while $63.12 \%$ had incidences of trace to $0.2 \%$ and only 20 acres had $0.2 \%$ infection. Out of 104 wheat seed sample tested by the embryo count technique, 15 contained dormant mycelium of the pathogen, with an infection range of 0.05-0.2 \%. Infection was highest in cv. Fd-85 from the Sahiwal area. Fewer seed samples were found to be infected in the southern Punjab than in central areas. Similarly, for the environmental factors such as maximum temperature, minimum temperature, relative humidity and rainfall play a very important role in disease development. Literature showed that the optimum temperature for loose smut of wheat is 22 to $27^{\circ} \mathrm{C}$ and maximum relative humidity for loose smut required for disease development is range from 60 to 90 \% (Druzhin and Krupnov, 2002).

\section{ACKNOWLEDGMENT}

This manuscript is a part of thesis of Mr. Rasheed Ahmed submitted to Department of Plant Pathology, Faculty of Agricultural Sciences and Technology, Bahauddin Zakariya University, Multan.

\section{REFERENCES}

Aggarwal, R., K. Srivastava, P. Bhadur and D. Singh. 1998. Resistance of loose smut and rust in wheat. Barley and Wheat Newsletter.

Beniwal, M. S., S. S. Karwasra and R. D. Parashar. 2009. Effect of sowing date on the incidence of flag smut of wheat in Haryana. Crop Research, 5: 598-600.

Bhutta, A. and S. Ahmad. 1991. A report on the incidence of loose smut in wheat crop and seed in some parts of the Punjab Province, during 1990-91. Pakistan Journal of Phytopathology, 3: 7-11.

Druzhin, A. and V. Krupnov. 2000. Influence of the environment on the infection of soft spring wheat by loose smut in the Cis-Volga Region. Russian Agricultural Sciences: 16-19.

Ghaffar, A. and S. Shahzad. 1992. Status of plant pathology in Pakistan. National Symposium on Status of Plant Pathology in Pakistan (1991: University of Karachi). Dept. of Botany, University of Karachi.

Hassan, S. F., N. A. Khan, M. Arshad, Anwar and Mahmood. 1970. A note on occurrence of physiological race 2 of Ustilag tritici (Pers) Roster West Pakistan Journal of Agricultural Research, 8: 218-219. 
Ilyass, M., M. Ahmad and M. Bajwa. 1990. Evaluation of inoculation methods and screening of wheat germplasm against loose smut of wheat. Pakistan Journal of Agricultural Sciences, 27: 252-256.

Ivanova, E. A., V. G. K and T. N. B. 2004. Physiologobiochemical analysis of pathogenesis of loose smut of wheat at early infection stages. Seryya Biyalagichnykh Navuk, 4: 69-73.

Kumar, V. and B. Singh. 2002. Successful management of loose smut of wheat. seed, 17:51-56.

Madden, L. V., G. Hughes and F. Bosch. 2007. The study of plant disease epidemics. American Phytopathological Society (APS Press).

Mishra, R., S. Tiwari and M. Khare. 1990. Studies on loose smut of wheat. X. Testing of resistance and susceptibility of wheat varieties to Ustilago tritici (Pers.) Rostr. under artificial inoculation. Indian Journal of Mycology and Plant Pathology, 20.
Ohaffar, A. and S. Shahzad. 1992. Major Seed-Borne Diseases of Wheat in Pakistan. Status of Plant Pathology in Pakistan: 111.

Piepenbring, M., R. Bauer and F. Oberwinkler. 1998. Teliospores of smut fungi general aspects of teliospore walls and sporogenesis. Protoplasma, 204: 155-169.

Singh, R., M. Beniwal, S. Karwasra and H. S. Saharan. 2009. Effect of sowing date on the incidence of loose smut, flag smut and seed gall of wheat. Bangladesh Journal of Agricultural Research, 34: 1-4.

Steel, R. G., J. H. Torrie and D. A. Dickey. 1997. Principles and procedures of statistics: A biological approach. McGraw-Hill.

Zia Ullah, H. M., A. H. Tariq, S. Ahmad, M. A. Hussain and L. H. Akhtar. 2003. Prospects for resistance to loose smut of wheat in southern Punjab. Ann. Wheat News. p: 89-92. 